\title{
A Rare Presentation of Heterotopic Pregnancy Presenting at Different Periods in the Same Embryo Transfer Cycle
}

\author{
Parameswara Iyer Ramesh ${ }^{1}$, Gopinathan Kannoli ${ }^{2}$, Soumya Nair ${ }^{3}$, Asha Anil Menon ${ }^{4}$
}

\begin{abstract}
Background: Heterotopic pregnancy (HP) is a rare complication of conceptions following ovarian stimulation. Its incidence is increasing with the use of assisted reproductive techniques (ART).

Case description: We are reporting a rare presentation of bilateral ectopic pregnancies together with intrauterine pregnancy which resulted from the transfer of three embryos in a single fresh transfer cycle. The presentation was unique because the pregnancies presented at different times. The intrauterine pregnancy (miscarriage) and the left ectopic pregnancy (EP) presented earlier and the right EP presented late. This is possibly due to the differential implantation and growth potential of the three embryos obtained from a single ART cycle. The patient had to undergo laparoscopy twice in a gap of 12 days.

Conclusion: A high index of suspicion will help to decrease the consequences of HP, especially in ART cycles. Elective single embryo transfer would be the best preventive measure.

Clinical significance: An early diagnosis of HP will help to prevent the dilemmas associated with it. Meticulous sonography and careful inspection of the contralateral tube should be the dictum in cases of HP.

Keywords: Artificial reproductive techniques, Embryo, Heterotopic pregnancy, Implantation potential.

International Journal of Infertility and Fetal Medicine (2020): 10.5005/jp-journals-10016-1209
\end{abstract}

\section{INTRODUCTION AND BACKGROUND}

Heterotopic pregnancy (HP) is defined as the presence of simultaneous intra- and extrauterine pregnancies. ${ }^{1}$ The incidence of HP after spontaneous conception is 1:10,000 to 1:30,000, while it increases to 1:100 after assisted reproductive techniques (ART). ${ }^{2,3}$

Assisted reproductive technique is a chief predisposing factor for HP. The main problem here is a diagnostic difficulty because the commonly used modalities for diagnosing ectopic pregnancy (EP) like $\beta$-hCG or transvaginal ultrasonography (TVS) may fail to identify HP. Transvaginal ultrasonography is often diagnostic but can miss it especially in the presence of hyperstimulated ovaries in ART cycles. ${ }^{4}$ About $50 \%$ of HP present with tubal rupture because of the inability to diagnose it precisely. ${ }^{5}$

\section{Case Description}

Mrs. X, 32 years of age, presented with primary infertility. Her husband was having oligoasthenoteratozoospermia and they already underwent 10 cycles of intrauterine insemination from some private clinic. Hysterolaparoscopy done 2 years ago was reported normal. She was counseled for ART and was put on long protocol using Leuprolide acetate (Inj LUPRIDE $0.5 \mathrm{mg}$ subcutaneously daily) from cycle day 21. After pituitary desensitization, she was stimulated with gonadotropin injections per day (hMG 150 IU, Inj IVF-M, LG Life sciences) for 10 days. Folliculogenesis was monitored using sonography and serum estradiol level. The final trigger was given with hCG 10,000 units (Inj. OVUNAL HP, Intas, India) and oocyte retrieval was done 36 hours later.

Twelve oocytes were obtained of which eight were mature (MII). Intracytoplasmic sperm injection (ICSI) was done using the husband's ejaculated sperm and she got three grade one embryos on day 2. The remaining five oocytes had 2PN arrest (one), 2 cell arrest (two), or were of poor grade on day 2 (two). All three grade one
${ }^{1}$ Department of Reproductive Medicine, IQRAA Fertility, IQRAA International Hospital and Research Centre, Kozhikode, Kerala, India

${ }^{2,3}$ Department of Reproductive Medicine, CIMAR, Edappal Hospitals Private Ltd, Malappuram, Kerala, India

${ }^{4}$ Department of Obstetrics and Gynaecology, Edappal Hospitals Private Ltd, Malappuram, Kerala, India

Corresponding Author: Parameswara lyer Ramesh, Department of Reproductive Medicine, IQRAA Fertility, IQRAA International Hospital and Research Centre, Kozhikode, Kerala, India, Phone: +91 9249426575, e-mail: drrameshp07@gmail.com

How to cite this article: Ramesh PI, Kannoli G, Nair S, et al. A Rare Presentation of Heterotopic Pregnancy Presenting at Different Periods in the Same Embryo Transfer Cycle. Int J Infertil Fetal Med 2020;11(3):76-78.

Source of support: Nil

Conflict of interest: None

embryos were transferred on day 2 (as per the institute's protocol) and she was put on luteal support with vaginal progesterone gel (CRINONE gel 8\%, Merck Serono). Pregnancy was confirmed by $\beta$-hCG done on the 14th day after embryo transfer (ET). The value obtained was $99 \mathrm{IU}$. It was repeated on day 21 of ET [5 weeks gestational age (GA)] and the value was $895 \mathrm{IU}$.

She had severe abdominal pain on the 27 th day of ET ( $5 w+$ 6d) for which transvaginal sonography was done for pregnancy localization. It showed a small intrauterine gestational sac (GS) with yolk sac (YS) and an absent fetal pole. There was a left adnexal mass $3 \times 2 \mathrm{~cm}$ (Fig. 1) with GS with increased Doppler flow around the mass. She was diagnosed as having HP and laparoscopy was done. Around $100 \mathrm{~mL}$ of hemoperitoneum was present and the left tubal mass was seen oozing from the tubal end (Fig. 2) and left

(0) Jaypee Brothers Medical Publishers. 2020 Open Access This article is distributed under the terms of the Creative Commons Attribution 4.0 International License (https://creativecommons.org/licenses/by-nc/4.0/), which permits unrestricted use, distribution, and non-commercial reproduction in any medium, provided you give appropriate credit to the original author(s) and the source, provide a link to the Creative Commons license, and indicate if changes were made. The Creative Commons Public Domain Dedication waiver (http://creativecommons.org/publicdomain/zero/1.0/) applies to the data made available in this article, unless otherwise stated. 


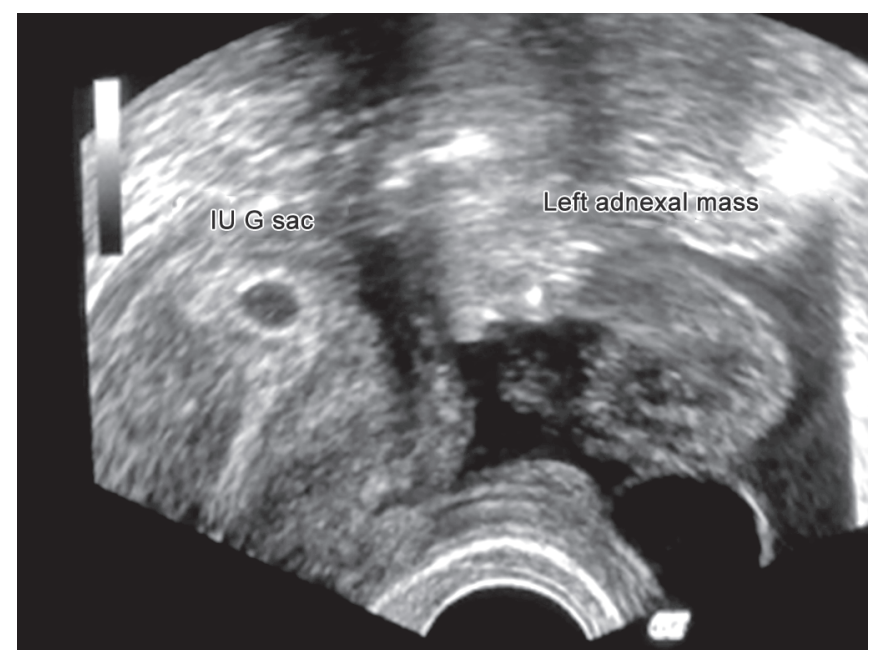

Fig. 1: Ultrasonography showing heterotopic pregnancy

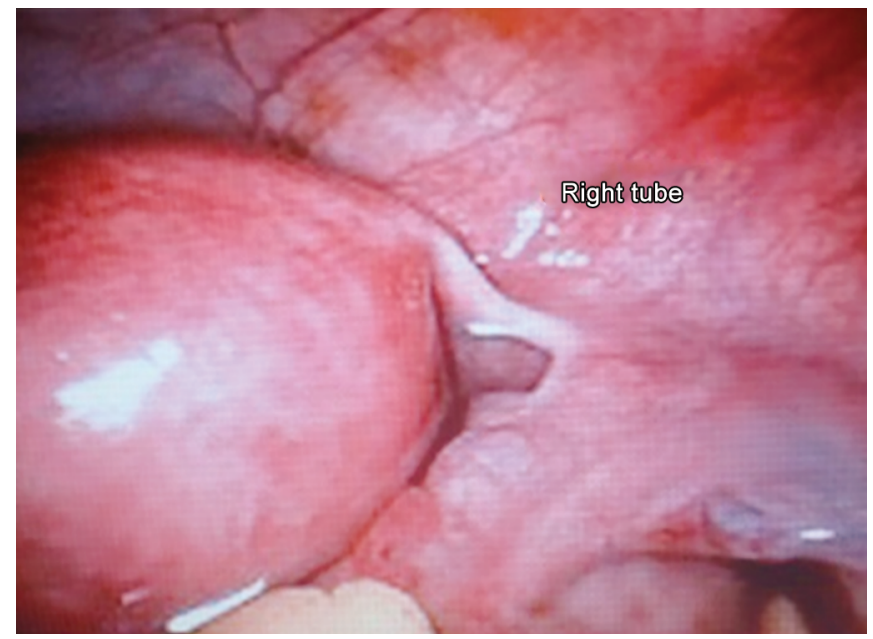

Fig. 3: Normal-looking right tube

salpingectomy was done. The right tube was found normal with some congestion (Figs 3 and 4).

Follow-up sonography was done 3 days later $(6 w+2 d)$ which showed intrauterine GS as before with no fetal pole. $\beta$-hCG was done, the value obtained was 1,694 IU. hCG and sonography were done 4 days later ( 6 w $6 \mathrm{~d}$ ). The value obtained was 2,443, which was showing an increase but not doubling. Sonography showed the same findings of intrauterine GS with absent fetal pole.

Two days later ( $7 \mathrm{w} 1 \mathrm{~d})$, she had mild abdominal pain again. $\beta$-hCG was 2,468 IU. Sonography showed intrauterine GS the same as before. There was a right adnexal mass of $2.5 \times 2.5 \mathrm{~cm}$. Considering possible miscarriage together with suspicious right $E P$, injection methotrexate $50 \mathrm{mg}$ was given intramuscularly.

Four days later ( $7 w 5 d), \beta$-hCG was repeated which showed a plateauing value of 2,450 . That day at midnight, she had severe abdominal pain and sonography revealed right adnexal EP with good Doppler flow. Emergency laparoscopy and salpingostomy were done (Table 1).

\section{Discussion}

This patient presented with intrauterine pregnancy along with bilateral EP following the transfer of three embryos in a single cycle

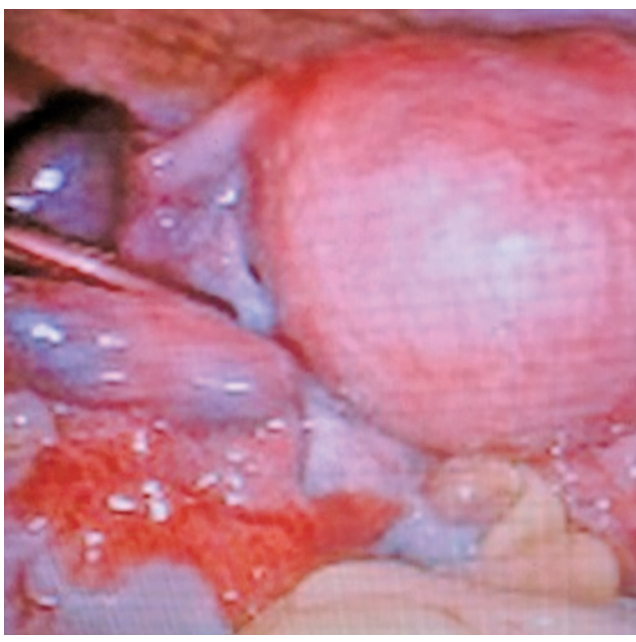

Fig. 2: Left ectopic pregnancy

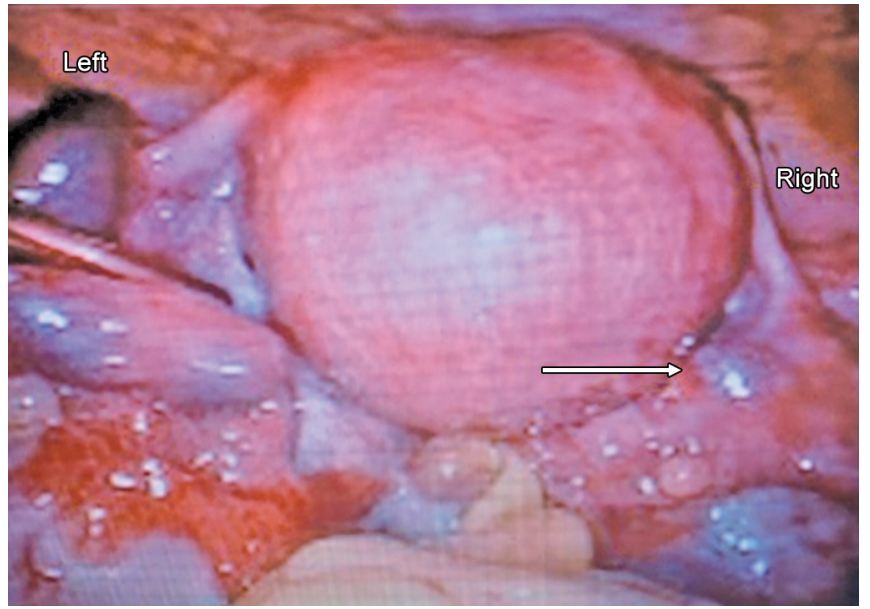

Fig. 4: Re-look of video image of 1st laparoscopy. Left ectopic pregnancy plus right tube showing an area of congestion. Surrounding pelvic congestion is also evident

Table 1: Events on different days after ET

\begin{tabular}{|c|c|c|c|}
\hline Day after ET & $G A$ & $\beta-h C G(I U)$ & Remarks \\
\hline 14 & $4 w$ & 99 & Support continued \\
\hline 21 & $5 w$ & 895 & \\
\hline \multirow[t]{2}{*}{27} & $5 w+6 d$ & - & SIUG sac with YS, No FP \\
\hline & & & $\begin{array}{l}\text { Left mass } 3 \times 2 \mathrm{~cm} \text {, Lap } \\
\text { salpingectomy done }\end{array}$ \\
\hline \multirow[t]{2}{*}{30} & $6 w+2 d$ & 1,694 & SIUG sac with YS, No FP \\
\hline & & & No doubling \\
\hline \multirow[t]{2}{*}{34} & $6 w+6 d$ & 2,443 & SIUG sac with YS, No FP \\
\hline & & & No doubling \\
\hline \multirow[t]{2}{*}{36} & $7 w+1 d$ & 2,468 & $\begin{array}{l}\text { Right adnexal mass } \\
2.5 \times 2.5 \mathrm{~cm}\end{array}$ \\
\hline & & & Methotrexate given \\
\hline 40 & $7 w+5 d$ & 2,450 & $\begin{array}{l}\text { Right adnexal active ectopic } \\
\text { pregnancy, laparoscopy }+ \\
\text { salpingostomy done }\end{array}$ \\
\hline
\end{tabular}

ET, embryo transfer; GS, gestational age; YS, yolk sac; SIUG, single intrauterine gestation 
of embryo transfer. One embryo got implanted in the uterine cavity, whereas the other two implanted one in each tube. However, the left EP presented first followed by the right one around 10 days later. Left salpingectomy was done initially during which the right tube looked normal except for a small area of congestion. This was noticed on the review of the first laparoscopic video and was mostly overlooked during the first surgery owing to the normal-looking right tube. The patient then underwent repeat laparoscopy for the right EP 12 days later. The intrauterine pregnancy ended up in a miscarriage.

This indicates the differential growth of embryos even if they are obtained from a single ART cycle. It also warrants a careful inspection of the contralateral tube in the context of the management of EP, especially in ART cycles.

Sherman et al. reported a similar case presenting with ruptured EP on one side and unruptured EP on the other side. ${ }^{6}$ But in our case, the pregnancy in the contralateral side presented after a gap of 10 days. The tubal congestion on the opposite side was not suspicious of pregnancy as it is seen in presence of an intrauterine pregnancy too, as part of generalized pelvic congestion. The question for debate here is what would have been done in this case if we were suspecting the presence of EP in the contralateral tube also which showed just an area of congestion. On review of the first laparoscopy video, the right tubal area of congestion was probably a small bulge that was overlooked. Whether we are justified in proceeding with a salpingostomy in the situation or just leaving it for a follow-up? Surgically administered medical management would have been an option. In any case, careful identification and documentation are very important as otherwise we may miss the finding and it will be extremely difficult to counsel the patient for a repeat laparoscopy in such a short period.

Tubal pregnancies may not develop cardiac activity at the same time as intrauterine pregnancies. This might be attributed to the tubal lining which might not be as supportive as the endometrium for embryo growth. However, the bilateral tubal pregnancies presenting in such a long gap may be due to the differential growth potential of the embryos. A high index of suspicion and careful rather than a casual inspection is warranted in all ectopic pregnancies especially in ART cycles.

The history of multiple cycles of failed intrauterine inseminations (IUIS) resulting in multiple intrauterine manipulations might have contributed to mild degrees of salpingitis which is a predisposing factor for HP. ${ }^{7}$ Pelvic inflammatory disease (PID) and previous EP as risk factors are consistent with the findings of other studies. ${ }^{8,9}$ So, any patient with a history of established or possible PID needs to be put in a high index of suspicion of having HP.

With the advent of high-resolution sonography, we might be able to identify similar cases but only if we carefully look for them. We also stress the importance of elective single or double embryo transfer in ART cycles considering the background of increased heterotopic pregnancies in these cycles. Several researchers have opined that HP may be more likely after ART because multiple embryos are transferred, along with a large volume of culture media. ${ }^{10,11}$ However, other studies have shown that the number of embryos transferred does not affect the actual incidence of $\mathrm{HP}^{12}$ The risk of EP is reported to be lower with the transfer of a single frozen blastocyst ${ }^{13,14}$ which indirectly might lower the HP incidence as well.

\section{Conclusion}

The possible differential growth potential of embryos can create bizarre situations. A high index of suspicion in those at risk for HP is important in the prevention and management of similar incidents. The routine practice of meticulously searching for extrauterine pregnancy even in presence of an intrauterine sac should be employed especially in ovarian stimulation and ART cycles. The policy of elective single embryo transfer would be a good preventive measure against the occurrence of HP.

\section{Clinical Significance}

An early diagnosis of HP will help to prevent the dilemmas associated with it. Meticulous sonography will help to identify it earlier. Careful inspection of the contralateral tube should be the dictum in cases of HP especially in cases with a transfer of multiple embryos.

\section{References}

1. Rojansky N, Schenker JG. Heterotopic pregnancy and assisted reproduction - an update. J Assist Reprod Genet 1996;13(7):594. DOI: 10.1007/BF02066615.

2. Alptekin H, Dal Y. Heterotopic pregnancy following IVF-ET: successful treatment with salpingostomy under spinal anesthesia and continuation of intrauterine twin pregnancy. Arch Gynecol Obstet 2014;289(4):911-914. DOI: 10.1007/s00404-013-3099-y.

3. Luo X, Lim CED, Huang $C$, et al. Heterotopic pregnancy following in vitro fertilization and embryo transfer: 12 cases report. Arch Gynecol Obstet 2009;280(2):325-329. DOI: 10.1007/s00404-008-0910-2.

4. Seeber BE, Barnhart KT. Suspected ectopic pregnancy. Obstet Gynecol 2006;107(2 Pt 1):399. DOI: 10.1097/01.AOG.0000198632. 15229.be.

5. Barrenetxea G, Barinaga-Rementeria L, Lopez de Larruzea A, et al. Heterotopic pregnancy: two cases and a comparative review. Fertil Steril 2007;87(2):417.e9. DOI: 10.1016/j.fertnstert.2006.05.085.

6. Sherman SJ, Werne RM, Hussain M. Bilateral ectopic gestations. Int J Gynecol Obstet 1991;35(3):255-257. DOI: 10.1016/00207292(91)90295-G.

7. Goldstein JS, Ratts VS, Philpott T, et al. Risk of surgery after use of potassium chloride for treatment of tubal heterotopic pregnancy. Obstet Gynecol 2006;107(2 Pt 2):506. DOI: 10.1097/01. AOG.0000175145.23512.5e.

8. Liu M, Zhang X, Geng L, et al. Risk factors and early predictors for heterotopic pregnancy after in vitro fertilization. Sun Q-Y, ed. Plos ONE 2015;10(10):e0139146.

9. Jeon $\mathrm{JH}$, Hwang $\mathrm{YI}$, Shin $\mathrm{IH}$, et al. The risk factors and pregnancy outcomes of 48 cases of heterotopic pregnancy from a single center. J Korean Med Sci 2016;31(7):1094. DOI: 10.3346/jkms.2016.31.7.1094.

10. Tummon IS, Whitmore NA, Daniel SA, et al. Transferring more embryos increases risk of heterotopic pregnancy. Fertil Steril 1994;61(6):10651067. DOI: 10.1016/S0015-0282(16)56757-0.

11. Verhulst G, Camus M, Bollen N, et al. Analysis of the risk factors with regard to the occurrence of ectopic pregnancy after medically assisted procreation. Hum Reprod 1993;8(8):1284-1287. DOI: 10.1093/ oxfordjournals.humrep.a138242.

12. Marcus SF, Macnamee M, Brinsden P. Heterotopic pregnancies after in-vitro fertilization and embryo transfer. Hum Reprod 1995;10(5):1232-1236. DOI: 10.1093/oxfordjournals.humrep.a136125.

13. Ishihara O, Kuwahara A, Saitoh H. Frozen-thawed blastoc transfer reduces ectopic pregnancy risk: an analysis of single embryo transfer cycles in Japan. Fertil Steril 2011;95(6):1966-1969. DOI: 10.1016/j. fertnstert.2011.02.015.

14. Li Z, Sullivan EA, Chapman M, et al. Risk of ectopic pregnancy lowest with transfer of single frozen blastocyst. Hum Reprod 2015;30(9):2048-2054. DOI: 10.1093/humrep/dev168. 